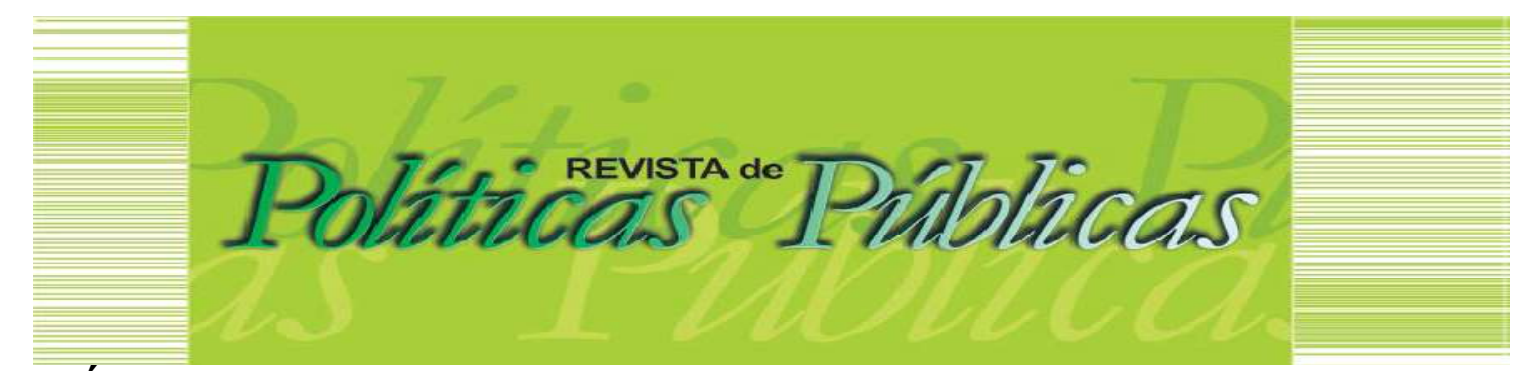

\title{
FAMÍLIA, HOMOSSEXUALIDADE E CONSERVADORISMO: discursos no Congresso Nacional brasileiro
}

\author{
Claudio Henrique Miranda Horst ${ }^{1}$
}

\begin{abstract}
Resumo
O artigo analisa os discursos que atravessam os projetos de lei no Congresso Nacional, que propõem regulamentar a união civil/casamento entre pessoas do mesmo sexo buscando identificar as características que esses discursos assumem. Pesquisa documental envolvendo sete projetos de lei que foram propostos entre 1995-2013. As defesas expressaram hegemonicamente a negação da totalidade da vida social, ocultando as determinações sociais, econômicas, políticas e culturais, advindas do modo de produção que afetam as famílias, atribuindo às famílias homoparentais a "culpa" por uma suposta "crise" ou "desestruturação" da família nuclear. Defendem uma concepção de família patriarcal, justificada pelo desejo de procriação, tido como natural e constituído apenas entre homens e mulheres.

Palavras-chave: Familia. Congresso Nacional Brasileiro. Família Homoparental.
\end{abstract}

FAMILY, HOMOSEXUALITY AND CONSERVATISM: discourses at the Brazilian National Congress

\section{Abstract}

This article analyses discourses that pass through bills of law on the National Congress, proposing the regulation of civil/marriage union/partnership between people of the same sex, aiming to identify the characteristics assumed by those discourses. Documental research evolving seven bills of law that were issued between 1995-2013. Their pleads have expressed mostly the denial of totality of social life, hiding social, economic, political and cultural determinations originated from capitalism, that affect families, and attributing to homoparental families the "blame" for a supposed "crisis" or "restructuring" of families. They've defended a concept of patriarchal family, justified by the desire of procreation, conceived as natural and constituted only of men and women

Keywords: Family. Brazilian National Congress. Homoparental Family.

Artigo recebido em: 18/08/2019 Aprovado em: 27/01/2020 DOI: http://dx.doi.org/10.18764/2178-2865.v24n1p366-384.

\footnotetext{
${ }^{1}$ Assistente Social. Doutor em Serviço Social pela UFSC. Mestre em Política Social pela UFES. Professor Adjunto do Departamento de Serviço Social da Universidade Federal de Ouro Preto (UFOP). Endereço: Rua do Catete, Centro, 35420000 - Mariana, MG - Caixa-postal: 166. E-mail: claudiovasques1@hotmail.com.
} 


\section{INTRODUZINDO: “ENQUANTO OS HOMENS EXERCEM SEUS PODRES PODERES”...}

Enquanto os homens exercem seus podres poderes, índios, padres e bichas. Negros e mulheres. E adolescentes, fazem o carnaval (Caetano Veloso - Podres Poderes).

Segundo Mészáros (2009), em um cenário onde o capital é capaz de se afirmar com êxito, como a força controladora do sociometabolismo, é de suma importância que as figuras representativas do horizonte do capital conceituem, discursem e defendam as questões postas na sociedade de uma determinada maneira. Nesse sentido, a relação entre "estrutura social e as formas de consciência é seminalmente importante" (MÉSZÁROS, 2009, p. 17), já que a estrutura social dada constitui o cenário e o horizonte dos sujeitos políticos e pensadores.

\footnotetext{
A análise legítima dos diversos discursos - por exemplo, os discursos moral, político e estético - é inconcebível sem que esteja dialeticamente inserida no quadro estrutural apropriado no que se refere às determinações gerais. Pois os discursos particulares não são inteligíveis sem que sejam apreendidos como formas específicas de consciência histórica (MÉSZÁROS, 2009, p. 17, grifo nosso).
}

Nessa direção, nosso objetivo na presente reflexão é analisar os discursos produzidos no Congresso Nacional (CN) brasileiro no interior dos projetos de lei que propõem a regulamentação do casamento entre pessoas do mesmo sexo ${ }^{1}$.

Cabe assinalar que o Supremo Tribunal Federal (STF), em maio de 2011, julgou a Arguição de Descumprimento de Preceito Fundamental (ADPF) 132 e a Ação Direta de Inconstitucionalidade (ADI) 4277, reconhecendo a união estável homoafetiva como entidade familiar. 0 Brasil reconheceu, assim, a união homoafetiva com os mesmos direitos dos casais heterossexuais. $E$ em maio de 2013, visando fortalecer a decisão do STF, o Conselho Nacional de Justiça aprovou resolução que obriga todos os cartórios do Brasil a realizar casamentos homoafetivos. A resolução 175, de 2013, dispõe sobre a habilitação, celebração de casamento civil, ou de conversão de união estável em casamento, entre pessoas de mesmo sexo. Contudo, ainda não temos nenhuma legislação que assegure em lei esse direito.

Quanto ao procedimento metodológico, realizamos pesquisa documental a partir de sete projetos de leis, os pareceres das comissões e os discursos realizados no plenário do $\mathrm{CN}$ durante os debates/votações. Procedemos à leitura de cada documento e sistematizamos os dados iniciais em roteiros de análise documental. Posteriormente, para análise, foi utilizada a técnica da análise de conteúdo. Desse total de sete projetos, quatro foram arquivados e/ou retirados de pauta (PL 1.151/1995; PEC 70/2003, PL 2.153/2011 e PLS 612), dois tramitam em conjunto com o PL 580 (PL 4.914; PL 5.120). 
O artigo está organizado em três momentos: no primeiro momento apresentamos o Congresso Nacional como um espaço de lutas na sociabilidade burguesa e seus limites; no segundo momento refletimos sobre as transformações da família, e, particularmente, a família homoparental na cena política; no último momento, apresentamos as justificativas favoráveis e contrárias ao reconhecimento das famílias homoparentais.

\section{2 "O REFLEXO IDEOLÓGICO DAS RELAÇÕES SOCIAIS VIGENTES": o Congresso Nacional Brasileiro}

De acordo com a Constituição Federal de 1988, o poder legislativo possui três funções essenciais: a) a de representar a populaçãa; b) a de legislar ou elaborar as leis; e c) a de fiscalizar e controlar a aplicação dos recursos públicos, em cujo exercício conta com o apoio do Tribunal de Contas da União - TCU. Esse poder configura-se, assim, como a representação política de uma nação, com o objetivo de garantir a representação popular (BONAVIDES, 2000).

0 poder de "fazer as leis" diz respeito ao poder de discutir em nome dos eleitores, já que se parte do entendimento que essa responsabilidade é transferida para seus representantes. Porém, sabemos que "a representação deforma-se, ou falseia-se, na medida em que se perdem as condições para a formação de uma vontade clara e nítida por parte do corpo eleitoral" (SALDANHA, 1992, p. 76).

Longe de considerar esse espaço como uma instância desconexa da sociabilidade vigente, concordamos com Coutinho (1996, p. 112) na compreensão que "a esfera da política é submetida à totalidade histórica, sendo impossivel entender adequadamente o que nela ocorre sem uma clara referência às demais esferas da sociedade, em particular à esfera das relações sociais de produção". Por isso, "não há democracia efetiva onde existe excessiva desigualdade material entre os cidadãos" (COUTINHO, 2006, p. 26).

Coutinho (2006) já nos alertava sobre os sistemas legislativos na democracia. Não basta estatuir e estudar somente as regras do jogo, pois o sistema econômico não permite que a regras sejam efetivamente democráticas; necessita-se de condições jurídicas e econômico-sociais para que tais regras e leis sejam efetivamente cumpridas. Ou seja, "a definição minimalista de democracia é uma mera ideologia, cujo objetivo principal é esvaziar a democracia do caráter subversivo e anticapitalista que, tanto teórica como praticamente, caracterizou-a desde sua origem" (COUTINHO, 2006, p. 27).

As leis, historicamente, sempre estiveram a serviço de uma dada noção de ordem, a serviço de concepções dominantes e, também, de interesses dominantes. Em outras palavras, sempre foram utilizadas como instrumento de controle social, como forma de preservação da organização social vigente. Todo 'poder legislativo' e suas competências, quando não acompanhados por uma base 
de eleitores ativos na cena política, por movimentos sociais, partidos da classe trabalhadora e outras organizações, podem - e têm sido utilizados - somente a favor dos interesses das classes dominantes.

O cenário político brasileiro tem demonstrado o esforço - ou o modo de como tem se dado o exercício da hegemonia - que alguns grupos têm realizado, no sentido de organizar no interior dos Legislativos, espaços como as frentes parlamentares ${ }^{2}$ que buscam concretizar na vida pública, a partir de leis, vetos e campanhas, os interesses desses grupos hegemônicos.

O projeto político em voga, direcionado em consonância com a ordem econômica, permite ao Estado um forte potencial de cooptação e supremacia, o que provoca no campo ideológico a despolitização das classes subalternas. Essa prática estava presente na legislação anterior (20152019) do Congresso Brasileiro, que foi considerado como o mais retrógrado e conservador desde a ditadura militar (RADIOGRAFIA DO CONGRESSO NACIONAL, 2015)3. Tais práticas no interior do CN, claramente "conservadoras, antidemocráticas e excludentes, levam a burguesia a fazer e refazer suas alianças, a romper os elos que unem as classes e seus dirigentes, tornando-os cúmplices da dominação burguesa e cerceando as possibilidades de formação de organizações revolucionárias" (SIMIONATTO, 1997, p. 7). No tocante, cabe ressaltar que a luta de classes na atual conjuntura não vem sendo travada mais em nome da conquista de novos direitos, mas, sim, na defesa daqueles já conquistados, e que estão sendo destruídos.

$\mathrm{Na}$ contramão dessa lógica, são os partidos, sindicatos, associações profissionais, movimentos sociais e sujeitos organizados que desempenham papel fundamental na disputa, sedimentada por interesses de classes, no esforço de barrar os poderes coercitivos do Estado capitalista. No interior do CN, as disputas dessas diversas organizações e entidades contribuem para "o alargamento da participação nos processos decisórios e o bloqueamento das estratégias de destruição dos direitos sociais e dos institutos de representação coletiva" (SIMIONATTO, 1997, p. 16).

Nesse sentido, aqui especificadamente, a luta pelo reconhecimento das diversas famílias chega ao CN por meio dos movimentos sociais de Lésbicas, Gays, Bissexuais e Transexuais (LGBT+), que, organizados coletivamente, vão exigir o reconhecimento dos seus direitos.

Ainda que disputas no interior do Estado não sejam em sua totalidade uma estratégia capaz de resistir às tendências destrutivas do capitalismo, tem sido uma das formas da organização coletiva que permite a realização da ação política. Afinal, conforme sabemos, a regulamentação de certos direitos não acontece naturalmente, mas sim como produto da correlação de forças e da articulação por meio de lutas institucionais no legislativo, populares e coletivas (SANTOS, 2005). Contudo:

[...] para que as lutas sociais em torno dos direitos humanos possam integrar uma cultura política emancipatória, as reivindicações particulares dos sujeitos e segmentos específicos não devem ser equacionados como um fim em si mesmo ou na condição de valores 
universais, mas inseridos na dinâmica da luta de classe, possam contribuir para revelar movimentos permanentes de tensão e contradição com a ordem vigente. Isso porque só faz sentido pensar nos direitos humanos se for para explicitar o estado de degeneração do tecido social, situação em que as condições matérias (objetivas e subjetivas) de vida de amplos segmentos tende a mais perversa degradação (SANTOS, 2005, p. 93, grifo nosso).

Nessa direção, os PLs, aqui selecionados, ao exigir o posicionamento das/os legisladores sobre o reconhecimento das famílias homoparentais, obrigou-os a discursarem sobre suas concepções de família e sexualidade. Tal disputa trata-se de algo caro à classe dominante e a seus representantes. Nosso papel nesse cenário é apontarmos o caráter histórico e contraditório dessa instituição e suas transformações.

\section{TRANSFORMAÇÃO DAS FAMÍLIAS E A FAMÍLIA HOMOPARENTAL}

Sabemos que as organizações familiares são construções históricas, que vão se modificando em cada tipo de sociedade e sofrem transformações, sejam econômicas, culturais, ideológicas, políticas, etc. De acordo com as transformações ocorridas nos modos de produção e organização da sociedade, as famílias vão sendo afetadas diretamente, pois como não há sociedades sem indivíduos, nem indivíduos sem sociedades, também não há desenvolvimento social que não interfira nos indivíduos (LESSA, 2012).

Se pensarmos numa perspectiva histórica, é importante salientar que todos os progressos da humanidade se deram juntamente com a ampliação das formas de subsistência, ou melhor, das forças produtivas que se inserem em relações de caráter técnico e relações de caráter social, estreitamente vinculadas e que constituem as relações de produção (NETTO; BRAZ, 2012).

Contudo, foi com o surgimento da família nuclear burguesa, baseada no amor romântico, que se estende como modelo dominante por toda a Europa ocidental, que as relações familiares se transformaram ainda mais (ENGELS, 2012). Concomitante e posteriormente, tivemos a construção da homossexualidade como "categoria sociopsicológica e do homossexual como identidade médica psiquiátrica" (MELLO, 2005, p. 42).

Simultaneamente à organização da família moderna em torno das figuras do pai, da mãe e dos filhos, iniciou-se um processo de construção social que culmina com a naturalização da divisão dos indivíduos em heterossexuais e homossexuais. Enquanto os homens e as mulheres que escolhem seus iguais biológicos como parceiros afetivo-sexuais passam a ser definidos como portadores de uma doença, o homossexualismo - estando, por sua própria "natureza doentia", incapacitados para a constituição de núcleos familiares -, a família burguesa assume para si o monopólio do amor romântico, restringindo a possibilidade de afloramento desse sentimento à esfera da relação homem/mulher (MELLO, 2005, p.42, grifo nosso). 
A família, que ocupa um lugar central na reprodução social da ideologia, determina, a partir do convívio familiar, as formas de socialização, e dos valores que vão incidir na formação desses sujeitos, interferindo diretamente no desenvolvimento das sexualidades (SANTOS, 2002). Portanto, a relação entre sexualidades e família se dá também por esta última se constituir um núcleo afetivo, que é atravessado pelas determinações do capitalismo, moldando, inclusive as relações socioafetivas.

As práticas afetivo-sexuais, desenvolvidas entre indivíduos do mesmo sexo, têm potencial questionador sobre essa estrutura familiar, afinal, por intermédio dessas práticas, entra em discussão o questionamento da relação afetivo-sexual ter como principal finalidade a reprodução da espécie, assim como podem ser questionados os valores machistas e a própria estrutura hierárquica e de posse entre homens e mulheres, instituída pelo casamento monogâmico e pela dominação masculina, dentre outras questões (SANTOS, 2002, p.13).

Conforme apontou Mészáros (2002) a instituição familiar cumpre um papel importante enquanto um microcosmo que contribui para a manutenção do capitalismo.

O aspecto mais importante da família na manutenção do domínio do capital sobre a sociedade é a perpetuação - e a internalização - do sistema de valores profundamente iníquo, que não permite contestar a autoridade do capital, que determina o que pode ser considerado um rumo aceitável de ação dos indivíduos que querem ser aceitos como normais, em vez de desqualificados por 'comportamento não conformista' (MÉSZAROS, 2002, p. 271, grifo nosso).

Nesse sentido, apesar da potencialidade questionadora do modelo homoparental em relação ao nuclear patriarcal burguês, é preciso ter clareza que modificações e mudanças nas instituições, como no caso da família, "por mais bem intencionadas e profundas que possam parecer, não tem força para transformar o solo matrizador da formação sócio-econômica da sociedade" (SANTOS, 2002, p.13)2.

Segundo Roudinesco5 (2003), as experiências em relação às famílias constituídas por pessoas do mesmo sexo, até a década de 1970, não apresentavam visibilidade. A autora associa a luta em favor da descriminalização da homossexualidade - somada à luta do movimento de emancipação dos negros e das diversas etnias - a mudança desse cenário. Mesmo com todas as transformações já vivenciadas pelas famílias, as homoparentais, segundo a autora:

Transgrediam uma ordem procriadora que havia repousado por dois mil anos no princípio do logos separador e da diferença sexual. Pois a instituição familiar não podia, nessa época, escapar a seu princípio fundador: o acasalamento carnal entre um homem e uma mulher. Sob este aspecto, a invenção das famílias dita "homoparental" arriscava reavivar o grande terror de uma possível supressão da diferença sexual, que, como vimos, surgira no final do século XIX no momento de declínio da antiga autoridade patriarcal (ROUDINESCO, 2003, p.181, grifo nosso).

A sacralização das famílias demonstra certo desconhecimento da construção histórica dessa instituição no ocidente, já que o modelo tido como "sagrado" data de tempos bem recentes, como já demonstraram autores como Àriès (1981); Engels (2012); Donzelot (1980); Lessa (2012); 
Costa (2004). A família nuclear, que corresponde ao modelo de referência no ocidente, está apoiada na ideia biológica de procriação de crianças a partir de um homem e uma mulher. Assim, esse modelo familiar se impõe como modelo inquestionável, por estar associado ao fator biológico. Porém, pensar a família somente a partir da biologia requer considerar que até certo momento a ciência e a tecnologia não dispunham de avanços necessários para a produção por outros meios de filhos (inseminação artificial, bebê de proveta, etc.), ou seja, expressava o limite de uma dada época.

A associação ao biológico permitiu considerar o modelo nuclear como "unidade fundadora da sociedade", "célula germinativa da civilização" e o "suporte para a evolução da sociedade". Ocorre, então, que esse modelo passou a ser naturalizado como único, levando a crermos que crianças devem ser educadas apenas por um pai e uma mãe heterossexuais. $O$ que colocaria sobre as mesmas pessoas todas as outras características que envolvem a família como: fator biológico de procriação, parentesco, filiação e cuidados (ZAMBRANO, 2006).

O protagonismo dos sujeitos coletivos LGBT+, trilhado a partir de muita articulação e luta, vai culminar em defesas por leis num espaço permeado por controvérsias, polêmicas e disputas ideológicas. Esses diversos sujeitos, como demonstra Santos (2005, p. 17), "dependem do Estado para regular seus direitos, têm utilizado, frequentemente, táticas de pressão sobre os partidos políticos, sobre os poderes constituídos e sobre a opinião pública para que reconheçam que a heterossexualidade não é a única orientação sexual".

O conservadorismo que se faz presente no $\mathrm{CN}$, entendido como um conservadorismo contemporâneo, "não se apresenta como conservadorismo e, portanto, oculta e escamoteia sua raiz e seus conteúdos conservadores" (ESCORSIM NETTO, 2011, p. 16). Entendemos que o pensamento conservador não é um estilo de pensamento, a-histórico, e encontrado em qualquer tipo de sociedade. Também não pode ser confundido com formas intelectuais, como comportamentos que valorizam e defendem o existente, o que se configura como tradicionalismo (ESCORSIM NETTO, 2011). Segundo a autora, o pensamento conservador é particular de um tempo histórico, o tempo da configuração da sociedade burguesa, "em que operam movimentos e tensões em todas as esferas e instâncias sociais" (ESCORSIM NETTO, 2011, p. 40).

\footnotetext{
A argumentação conservadora, [...] praticamente não se alterou ao longo do século XIX, e pode ser resumida como se segue: 1) Só são legitimas a autoridade e a liberdade fundadas na tradição; 2) A liberdade deve ser sempre uma liberdade restrita; 3) A democracia é perigosa e destrutiva; 4) $\boldsymbol{A}$ laicização é deletéria; 5) A razão é destrutiva e inepta para organizar a vida social; 6) A desigualdade é necessária e natural (ESCORSIM NETTO, 2011, p. 63).
}

Ao considerarmos esses traços do conservadorismo, torna-se clara a importância da instituição família. E também de uma das características apontadas que considera normal a 
interferência da religião no Estado. Os conservadores compreendem a família como a base moral da sociedade, por onde se transmite valores e tradição. Consideram também que é por meio da estabilidade social das famílias, e do seu papel econômico, que as mesmas contribuem para a eternização da sociedade e do seu modo de organização (ESCORSIM NETTO, 2011).

A valorização da família, constante em todos os conservadores, está também conectada a um traço distintivo do pensamento conservador: a defesa da constituição de grupos intermediários, capazes de - junto com a família - mediar à relação entre os indivíduos e a sociedade. Tais grupos - associações, corporações [...] são, igualmente, a única garantia para assegurar a harmonia orgânica da sociedade, provendo os vínculos de solidariedade e coibindo as tendências sociais dispersivas; [...] (ESCORSIM NETTO, 2011, p. 66).

É nesse sentido que apontamos o caráter conservador do Congresso Nacional e a importância dada à família. Quando não colocada como central nas pautas, a família se faz presente nas defesas contrárias a pautas consideradas progressistas. Nesse contexto, diante da diversidade familiar - e entre eles, os casais homossexuais - que o Congresso Nacional é convocado a legislar sobre a possibilidade de reconhecimento dos diversos modelos de famílias no Brasil. É "nesse espaço - de quem decide o que é melhor para outros - que aflora a moralidade mais conservadora" (FONSECA, 2005, p. 57).

Nessa direção, a luta por direitos chega ao CN, e enquanto parte da sociedade civil, também é constituído como um espaço de luta de classes e disputas de hegemonia. A presença dos movimentos sociais se torna fundamental para o fortalecimento da luta no sentido de exigir dos deputados federais e senadores que apresentem propostas condizentes com a garantia de direitos, em busca de uma sociedade igualitária, visando, nas palavras de Coutinho (2006), pautas e estratégias de disputa pelo poder que sejam vinculadas à construção de uma nova hegemonia. Dito isso, torna-se necessário analisar os discursos que perpassam as disputas em torno do que muitos consideram privilégios a um setor da sociedade - a população LGBT+.

\section{AS JUSTIFICATIVAS FAVORÁVEIS E CONTRÁRIAS AO RECONHECIMENTO DAS FAMÍLIAS HOMOPARENTAIS}

Sabemos que no campo da discussão sobre famílias e diversidade sexual são as defesas morais-religiosas ${ }^{6}$ que predominam. No contexto brasileiro, historicamente marcado pela influência religiosa na esfera da política, há uma pluralidade de credos que disputam os espaços públicos, buscando a legitimação de suas práticas.

Cabe destacar que os discursos considerados por nós como conservadores, não são entendidos aqui como "traços de personalidade", ou tendências subjetivas, pois, "ao reduzir o 
conservadorismo a 'traços de personalidade', tende-se a se subtrair o conteúdo e o significado histórico, específico e contraditório, dessa corrente de pensamento e ação em relação à totalidade social" (SOUZA, 2015, p. 208).

Nesse sentido, o conservadorismo moderno deve ser entendido como "complexo ideológico oriundo das determinações do amadurecimento da hegemonia burguesa, que consubstancia elementos dispares para a naturalização da essência do modo de vida calcado na exploração do trabalho e nas opressões historicamente determinadas" (PINHEIRO, 2015, p.198).

Tratamos, então, de apresentar os discursos contrários e favoráveis ao reconhecimento das famílias homoparentais. Nossa exposição está organizada de forma que as defesas contrárias e as favoráveis em relação ao reconhecimento das famílias homoparentais - e agrupadas aqui em elementos comuns que apareceram nos discursos - possibilitem, posteriormente, a identificação da concepção de família de cada grupo. A análise dos dados revelou a manifestação de quatro tipos de argumentos favoráveis:

- A defesa pelo reconhecimento da diversidade e da existência das diversas famílias, em especial, da família homoparental.

Esses discursos se apresentam como progressistas ao demarcarem o reconhecimento da diversidade sexual e, ao mesmo tempo, da diversidade de famílias presentes na realidade brasileira. Esses posicionamentos expressaram, inicialmente, a defesa da existência da família homoparental, que, inicialmente, parece algo que não precisaria ser reforçado, afinal os homossexuais existem e constituem famílias. Porém, no cenário conservador, o grupo hegemônico no interior do CN tenta mascarar tais relações, acreditando que, ao negar a existência de tais famílias, estaria evitando seu aumento.

$O$ projeto visa o reconhecimento das relações entre pessoas do mesmo sexo, já que estes relacionamentos vêm se impondo cada vez mais na sociedade (DEPUTADA MARTA SUPLICY).

Os relacionamentos entre pessoas do mesmo sexo, denominados pela jurisprudência de homoafetivos, são uma realidade jurídica que têm contornos cada vez mais nítidos no Brasil (DEPUTADO JOSÉ GENOÍNO).

Destaca-se a palavra "realidade" como forma de contraposição a uma sociedade imaginada sem a existência desses casais. Ao diferenciar o modelo tido como natural da diversidade encontrada na realidade, esses discursos defenderam que o modelo homoparental foge à regra do que constitui o modelo nuclear desde seu princípio. Afirmam, também, que o fator principal desse novo modelo de família é o afeto, por isso, famílias homoafetivas. 0 afeto entra em cena como a justificativa para o reconhecimento 7 . Também foi defendido o reconhecimento desse modelo de família, devido ao fato de outros países já terem reconhecido. 
Nos países onde o Estado reconheceu o casamento civil entre pessoas do mesmo sexo, as novas gerações já crescem e se educam sabendo que gays e lésbicas não são melhores ou piores do que os heterossexuais, mas apenas diferentes e que suas famílias valem, para o Estado e para a sociedade, o mesmo que as famílias heterossexuais, e merecem o mesmo respeito e reconhecimento (JEAN WYLLYS E ERIKA KOKAY).

- A necessidade do Estado regular direitos e deveres dos casais homoafetivos.

O segundo ponto remete à defesa a partir da justificativa da necessidade de regulação por parte do Estado dos direitos do casamento entre pessoas do mesmo sexo. Historicamente no Brasil, diversos direitos foram negados a essa população, desde 0 acesso à seguridade social, até 0 direito à adoção, por exemplo. Cenário que vem se alterando devido à pressão do Movimento LGBT. Porém, muitas dessas conquistas se deram no âmbito das próprias autarquias ou instituições, como o INSS, ou nos governos municipais, estaduais, no judiciário. Tal fato remete-nos a situações que podem ser modificadas, como, por exemplo, o próprio casamento, a adoção, que apesar de serem reconhecidos no Brasil pelo STF, ainda não são garantidos por lei. Nesse sentido é que os legisladores defendem a aprovação pelo $\mathrm{CN}$.

Apesar de os discursos defenderem a proteção necessária para esses casais, o que segundo os deputados contrários não caberia em um PL, pois o Código Civil já garante certos direitos, alguns setores do movimento LGBT+ questionam a intenção da regulamentação pelo estado8.

- Pelos direitos fundamentais de cada indivíduo, reconhecido pela CF/88 e a defesa da laicidade.

Reforçaram que o direito ao casamento e a livre escolha amorosa devem ser garantidos, com base no que já existe em lei. Por isso, os direitos fundamentais garantidos em nossa CF/88 aparecem nos discursos como primordial em defesa do casamento.

A Carta Magna, já em seu art. $1^{\circ}$, eleva tanto a cidadania quanto a dignidade da pessoa humana à condição de fundamentos norteadores do Estado Democrático de Direito em que a República Federativa do Brasil, há mais de vinte anos, constituiu-se. 0 art. $3^{\circ}$, por sua vez, estabelece como um dos objetivos essenciais dessa mesma República a promoção do bem de todos, sem forma alguma de discriminação (DEPUTADA MARTA SUPLICY).

Certos princípios aparecem como fundamento da República e exigem, na visão desses legisladores, que os relacionamentos homoafetivos possam encontrar no Estado laico a devida proteção jurídica. Foi a partir da $\mathrm{CF} / 88$ que os legisladores defenderam o direito à igualdade, à luta contra toda forma de discriminação, bem como à dignidade humana, como algo que combate violação aos direitos humanos.

- Pela devida separação entre casamento (para heterossexuais) e união civil/parceria civil (entre pessoas do mesmo sexo) - com exceção do PL 5120/2013 da autoria de Jean Wyllys e Erika Kokay. 
Dos projetos de lei em debate, apenas o PL 5120 de 2013 apresentou a defesa pelo reconhecimento das famílias homoparentais e pela igualdade entre homossexuais e heterossexuais. Os termos parceria civil, união civil, parceria civil registrada, dizem respeito a uma nova forma de reconhecer a conjugalidade de casais homoafetivos, que no interior dos projetos deixava claro o que caberia a esses casais, e o que não seria "comparado" aos direitos já existentes em relação ao casamento.

$\mathrm{Na}$ visão dos legisladores, certas questões como matrimônio e casamento são implicações voltadas apenas para outra parte da população, demonstrando uma defesa equivocada do casamento como algo exclusivamente religioso. Cabe destacar que o casamento, como contrato civil, é anterior ao casamento religioso e, por isso, não foi invenção das religiões cristãs. Nesse sentido, "não cabe as religiões reivindicar qualquer poder legítimo com relação ao nome ou a instituição" (RIBEIRO, 2012, p. 66, grifos nossos).

Não há justificativa coerente para se criar um modo diferenciado de denominar relações essencialmente iguais, que não seja a tentativa de manutenção da desigualdade e do preconceito. Nesse sentido, no total de seis projetos sobre conjugalidade, apenas o PL 5120/2013 derruba essa lógica e propõe declaradamente o reconhecimento do casamento e da família.

\footnotetext{
Este projeto de alteração do Código Civil defende que o casamento civil entre pessoas do mesmo sexo deve ser o mesmo, deve ter os mesmos requisitos e efeitos, deve garantir os mesmos direitos e deve levar o mesmo nome que o casamento civil entre pessoas de distinto sexo. Rejeitamos fortemente qualquer tentativa segregacionista que pretenda manter a discriminação contra as pessoas homossexuais (DEPUTADO JEAN WYLLYS e DEPUTADA ERIKA KOKAY).
}

Assim, os discursos favoráveis à regulamentação pelo $\mathrm{CN}$ das famílias homoparentais defenderam uma concepção de família ampla, onde os diversos modelos são reconhecidos. Com base na defesa da cidadania, os discursos foram fundamentados pela $\mathrm{CF} / 88$ nos seus artigos iniciais e por documentos internacionais que defendem o combate à opressão, colocando os direitos sexuais no campo dos direitos humanos. Além disso, os discursos defenderam, majoritariamente, uma separação entre direitos para heterossexuais e homossexuais, ao afirmarem a garantia da união civil, em detrimento do casamento.

Em relação aos posicionamentos contrários, a análise dos dados revelou que a defesa parte de quatro argumentos principais, a saber:

- Com base numa concepção natural (positivista) e da moral religiosa, são contrários à 'desmoralização', 'desmantelamento' e 'destruição' que o reconhecimento da família entre pessoas do mesmo sexo pode causar à família concebida por Deus. 
A primeira justificativa, presente em todos os discursos contrários à diversidade familiar, está diretamente ligada à concepção religiosa. Apresenta, como princípio, a heterossexualidade compulsória, em que todos os indivíduos expressariam apenas desejo sexual e afetivo por pessoas do sexo oposto. Esse entendimento da homossexualidade carrega em si a compreensão do conceito de família.

\begin{abstract}
Conforme uma variante psicologizante destes discursos homofóbicos, as pessoas "nascem heterossexuais" e, em decorrência de fatores externos, como traumas familiares, tornam-se infelizes, deprimidas e instáveis, desenvolvendo desejos homossexuais por efeito dessas experiências passadas. A homossexualidade não é vista como uma identidade, mas como o sintoma de uma trajetória pessoal percorrida em ambientes que não correspondem ao modelo ideal da família cristã (NATIVIDADE; OLIVEIRA, 2009, p. 6).
\end{abstract}

O determinante para a definição da orientação sexual dos filhos, nessa lógica, seria a vivência em uma família "desestruturada". Segundo a interpretação dos legisladores, a formação da família, iniciada por Deus com Adão e Eva, e voltada para a procriação, é o princípio universal da humanidade e não caberia a um Estado passar por cima dessa 'lei'. Portanto, qualquer projeto de lei que se apresente como contrário aos ordenamentos bíblicos, aos olhos da bancada evangélica, visa atacar a família natural, nuclear, composta por indivíduos do sexo oposto com o objetivo de reprodução.

A desmoralização que se quer legalizar, o desmantelamento da família, com a instituição desta aberração contrária a natureza, que criou cada espécie com dois sexos, afronta os mais comezinhos princípios éticos da sociedade brasileira (DEPUTADO SALVADOR ZIMBALDI).

Parte-se do pressuposto, então, como apresentado no discurso, que os princípios éticos da sociedade brasileira não aceitam a diversidade familiar. Claro, princípios esses sustentados pela reprodução de um modelo que legitima a ordem dominante. Esse fato demonstra uma ausência de separação entre Estado e Igreja, visto que consideram as normas da sociedade brasileira como uma extensão da compreensão cristã.

É a destruição do sentido de família que é a base da sociedade. Deus, ao criar o homem e uma mulher, disse: crescei e multiplicai. Essa é a lei natural que o Estado apenas reconhece, pois é anterior ao próprio Estado. Querer mudar a lei natural é ir de encontro ao Criador e as consequências não tardarão (DEPUTADO SEVERINO CAVALCANTI).

Há uma percepção da bancada evangélica de que os diálogos entre organizações não governamentais, movimentos sociais e poder público representam uma articulação perigosa contrária aos valores cristãos.

Cremos firmemente que Deus nos criou e designou o casamento e a família como a mais fundamental das relações humanas. No mundo de hoje em dia, como no passado, as famílias são alvo daqueles que lutam contra os valores cristãos. 0 propósito básico de Deus para a família está descrito na bíblia. A família começa com o casamento (DEPUTADOS CAPITÃO ASSUNÇÃO E PAES DE LIRA). 
A defesa da família como base da sociedade e como propósito básico da vontade divina, na verdade, reforça o papel e a importância dessa instituição naquele entendimento que 'se a família vai mal, o país caminha mal'. Deslocando o centro das determinações sociais, modo de produção capitalista, para o interior de um modelo de família. Dessa forma, ao acusar o risco de desmantelamento da família nuclear, os discursos conservadores reafirmam o lugar privilegiado da família nuclear patriarcal na sociedade brasileira.

- Implicaria no reconhecimento da orientação sexual homo como algo normal e que visa ser naturalizado.

Outra justificativa que perpassou os discursos contrários foi o 'medo', segundo os legisladores, de que com a aprovação do casamento, a população LGBT+ passasse a ser reconhecida como pessoas 'normais'. Na perspectiva dos discursos, trata-se de pessoas doentes e/ou pecadoras que necessitam de ajuda. Caso ocorresse a naturalização da diversidade sexual, seria uma tragédia para a sociedade, uma vez que haveria o reconhecimento em forma de lei, essa família legitimaria, então, a orientação sexual de seus membros. Como nos alertam Natividade e Oliveira (2009, p. 22), 'tentativas de especificação das 'causas' da homossexualidade são pautadas pela necessidade de assegurar 0 estatuto de normalidade das pessoas heterossexuais, cuja hegemonia se vê ameaçada diante do confronto com manifestações da diversidade sexual".

- A defesa de inconstitucionalidade dos projetos.

Os discursos também se orientam na defesa de inconstitucionalidade dos projetos, baseados, principalmente, no artigo 226 da CF, que determina a família como constituída por homens e mulheres.

\begin{abstract}
Assim, qualquer proposição a ser apresentada, nesta Casa de leis, deve observar os princípios constitucionais, dentre eles as chamadas cláusulas pétreas, aqueles dispositivos explícitos ou implícitos que somente podem ser alterados, com tendência a aboli-los, diante de um novo Poder Constituinte Originário. [...] Ante as referências constitucionais supracitadas, não pode haver outro entendimento, senão no sentido de que família é a união entre homem e mulher (DEPUTADOS CAPITÃO ASSUNÇÃO E PAES DE LIRA).
\end{abstract}

Porém, outros juristas já demonstraram que certas leituras da CF expressam equívocos que ignoram os fundamentos principais da mesma, como igualdade e liberdade. Nas palavras do Ministro Ayres Britto, do STF, "as disposições constitucionais não emprestam ao substantivo 'família' nenhum significado ortodoxo ou da própria técnica jurídica, o que implica dizer, nessa mesma visão, que a Constituição não interdita a formação da família por pessoas do mesmo sexo".

- O risco, posteriormente, da adoção de crianças por casais do mesmo sexo. 
Vinculados à concepção de família - nuclear, natural, criada por Deus- a procriação é entendida como algo central na formação da família, desconsiderando-se a possibilidade da adoção e, até mesmo, do avanço da tecnologia, já que não existe "continuidade de vida por casais do mesmo sexo".

A adoção por casais homossexuais exporá a criança a sérios constrangimentos. Uma criança, cujos pais adotivos mantenham relacionamento homoafetivo, terá grandes dificuldades em explicar aos seus amigos e colegas de escola porque tem dois pais, sem nenhuma mãe, ou duas mães, sem nenhum pai (ZEQUINHA MARINHO).

Os discursos apontam a possibilidade das crianças serem alvos de repúdio e preconceito; tais fatos, segundo eles, afetariam o desenvolvimento das crianças. Como apresentado pelo deputado, há na concepção dominante a presença de um pai (homem) e uma mãe (mulher), dessa forma, haveria o exercício da parentalidade ocorrendo de forma plena.

Somente a família regularmente formada, constituída pelo homem e pela mulher, poderá exercer a influência correta na transmissão dos valores e das tradições (DEPUTADO MILTON CARDIAS).

Na legislatura de 2015 a 2019 do CN, o grupo conservador exerceu uma forte atuação para impedir a aprovação da adoção por casais homoafetivos. Isso, porque na concepção dos legisladores, como já sinalizado, é a presença da criança no interior da família que a define como tal. Os legisladores reverberam o discurso que, em última instância, o casamento sim, porém a adoção jamais 9 .

Ambiente familiar adequado, a condição estabelecida pela lei, significa ambiente moralmente sadio, onde se encontrem pessoas comprometidas com um único propósito: criar e educar o menor segundo os princípios ditados pela moral e pelos bons costumes. Nobres Deputados, é possível ter um ambiente sadio para a criança numa "família" formada por homossexuais? (DEPUTADO MILTON CARDIAS, PTB/RS).

Dentre esses valores, destacam-se o casamento monogâmico, o amor romântico e a constituição de família nuclear, tendo o pai como chefe-provedor, o que permite "hierarquizar as demais vivências das sexualidades a partir deste modelo, produzindo sujeitos coerentes a um sistema que vincula inexoravelmente sexo/gênero/desejo" (MESQUITA; PERUCCHI, 2016, p. 111).

Contudo, cabe destacar, conforme apontou Mészáros, que as famílias homoparentais, inseridas na lógica capitalista ainda que se defrontam com algumas questões, também reproduzem a lógica dominante, por meio das relações sociais de educação e cuidado. Em outras palavras, essa família não é capaz de transformar as estruturas da sociedade que regem as próprias determinações do que pode ou não ser aceito.

De modo geral, os discursos reforçaram uma concepção de família baseada na bíblia e criada por Deus, tida como natural, associada ao biológico, que permite considerar este modelo como fundador da sociedade, impõe-se como modelo inquestionável, por estar associado à procriação. 
FAMÍLIA, HOMOSSEXUALIDADE E CONSERVADORISMO: discursos no Congresso Nacional brasileiro

Nesse sentido, a figura do pai e da mãe foi defendida e, até mesmo, o amor, restringido à esfera homem-mulher. Ao mesmo tempo, foram vinculadas todas as características que envolvem uma família como: procriação, parentesco, filiação e cuidado sobre as mesmas pessoas.

\section{REFLEXÕES FINAIS}

As leis não bastam. Os lírios não nascem da lei. (Carlos Drummond de Andrade).

Ao reconhecermos o espaço importante de disputa que o legislativo federal representa e da importância da luta por direitos - dos quais dependem, cotidianamente, as famílias da classe trabalhadora - estamos cientes que esse espaço não é o terreno próprio de luta pela emancipação humana. Pois, "uma instituição conservadora desse gênero é por natureza totalmente incapaz de conceber, para não dizer efetivar, qualquer alteração radical do sistema vigente" (MANDEL, 1985, p. 348 , grifo nosso).

Nesse espaço, o fundamentalismo religioso ${ }^{10}$ vem ganhando maior expressão na atual conjuntura, defendendo um viés absoluto de determinadas crenças, expandindo-se no plano político com defesas intolerantes, "configurando-se como expressão funcional à manutenção de privilégios e da essência do binômio exploração/opressão em tempos de decadência ideológica e de crise estrutural do capital" (PINHEIRO, 2015, p. 198).

A análise, a partir das defesas contrárias e favoráveis ao reconhecimento de um modelo de família, permitiu-nos identificar os embates conceituais permeados na defesa de um modelo nuclear patriarcal burguês - embasado, também, a partir da bíblia cristã - versus, o reconhecimento não de um modelo, representado pelas famílias homoparentais, mas a defesa pela diversidade familiar.

Ao fim e ao cabo, as discussões assumiram uma posição limitada à defesa intransigente do casamento, remetendo-se, assim, apenas à esfera da pequena política, na compreensão gramsciana. Nesse sentido, faz-se urgente a vinculação dessa pauta a uma visão de totalidade, possibilitando, para além dessa questão em si, a discussão da grande política.

Notam-se discursos contrários com foco na ideia da família homoparental como causadora da 'crise' nas famílias, da 'desestruturação' das famílias, ocultando as determinações sociais, econômicas, políticas e culturais, advindas do modo de produção que as afetam hoje. Apesar de ser estratégico mistificar as determinações impostas pelo capitalismo, esses discursos também demonstram as limitações postas ao debate sobre famílias, principalmente, por não entendê-las como uma instituição contraditória (HORST, 2019). Afinal, negam um reconhecimento por acreditarem que tal modelo de família não reproduziria também os valores dominantes. 
Diante do exposto, é preciso urgentemente elaborar um projeto democrático a partir de alianças, com os mais diversos segmentos da sociedade civil, movimentos sociais, sujeitos políticos, vislumbrando a construção de alternativas à conjuntura posta. Parafraseando Simionatto, é necessário agregar vontades coletivas na defesa de projetos alternativos ao projeto dos dominantes.

Por fim, em consonância com a epígrafe que abre o presente artigo, enquanto os homens exercem seus podres poderes, seguiremos nas lutas, aproximando o nosso "cantar vagabundo, daqueles que velam pela alegria do mundo", na defesa de uma radical transformação social que possibilite outras vivências familiares que não as mesmas sob a égide do capital.

\section{REFERÊNCIAS}

ALMEIDA, M. V. O casamento entre pessoas do mesmo sexo. Sobre "gentes remotas e estranhas numa sociedade decente". Revista Crítica de Ciências Sociais, n.76, p.11-35. 2006.

ARIÈS, P. História Social da Criança e da Família. Tradução de Dora Flaksman. Edição Brasileira. Rio de Janeiro. LTC editora S. A. 1981.

BONAVIDES, P. Ciência Política. 10 ed. São Paulo: Malheiros Editores. 2000.

CORREAA, S. Interrogando a Laicidade. In: Fazendo Gênero 8. Anais Fazendo Gênero 8- Corpo, Violência e Poder. Florianópolis. 2008.

COSTA, A. B; NARDI, H. C. O casamento -homoafetivo e a política da sexualidade: implicações do afeto como justificativa das uniões de pessoas do mesmo sexo. Revista Estudos Feministas.

Florianópolis, v.23, n.1, 312, janeiro-abril, 2015.

COSTA, A. C. G. A família como questão social no Brasil. In: KALOUSTIAN, Sílvio Manoug (org.)

Família brasileira a base de tudo. 6 ed. São Paulo: Cortez, Brasília, DF: UNICEF, 2004.

COUTINHO, C. N. Marxismo e política: a dualidade de poderes e outros ensaios. 2. Ed. São Paulo: Cortez, 1996.

Representações de Interesses, Formulação de Políticas e Hegemonia. In: TEIXEIRA, S. F. Reforma Sanitária em busca de uma teoria. 3 ed. São Paulo: Cortez, 2006.

DONZELOT, J. A polícia das famílias. Tradução de M. T. da Costa Albuquerque; revisão técnica de J. A. Guilhon Albuquerque. Rio de Janeiro: Edições Graal, 1980.

ENGELS, F. A origem da família, da propriedade privada e do Estado. Tradução de Leandro Konder . 3 ed. São Paulo: Expressão Popular, 2012.

ESCORSIM NETTO, L. O conservadorismo clássico: elementos de caracterização e crítica. São Paulo: Cortez, 2011. 
FONSECA, C. Sexualidade, Família e Legalidade: questionando fronteiras. In: ÁVILA, M. B; PORTELLA, A. P; FERREIRA, V. Novas Legalidades e democratização da vida social: família, sexualidade e aborto. Rio de Janeiro: Garamond, , 2005. (Coleção sexualidade, gênero e sociedade).

HORST, C. H. M. Discursos sobre a adoção por casais homoafetivos no Congresso Nacional Brasileiro. Revista Argumentum, v.9, n.1, p.103-118, 2017. https://doi.org/10.18315/argum.v9i1.13723.

Família, Marxismo e Serviço Social: Desvendando o involúcro místico. Tese (Doutorado em Serviço Social), Universidade Federal de Santa Catarina, Programa de Pós-Graduação em Serviço Social, 2018.

LESSA, S. Abaixo a Família Monogâmica! São Paulo: Instituto Lukács, 2012.

MANDEL, E. 0 capitalismo tardio. 2. ed. São Paulo, Nova Cultural, 1985.

MELLO, L. Novas famílias: conjugalidade homossexual no Brasil contemporâneo. - Rio de Janeiro: Garamond, 2005. 232p. (Sexualidade, gênero e sociedade).

MESQUITA, D. T; PERUCCHI, J. Não apenas em nome de Deus: discursos religiosos sobre a homossexualidade. Revista Psicologia e Sociedade, v.28, n.1, p.105-114, 2016.

MÉSZÁROS, I. Para além do Capital. São Paulo: Boitempo Editorial. 2002.

Estrutura Social e formas de consciência. A determinação social do método. São Paulo, Boitempo, 2009.

NATIVIDADE, M; OLIVEIRA, L. Sexualidades Ameaçadoras: religião e homofobia (s) em discursos evangélicos conservadores. Revista Latino Americana Sexualidad, Salud e Sociedad, Rio de Janeiro, n. 2, p. 121-161, 2009.

NETTO, J. P; BRAZ, M. Economia política: uma introdução crítica. 8. ed. São Paulo: Cortez, 2012.

PINHEIRO, P. W. M. Serviço Social, Neoconservadorismo Religioso e o Desafio para a Formação Profissional. Temporalis, Brasília (DF), ano 15, n. 29, jan-jun. 2015.

RADIOGRAFIA DO NOVO CONGRESSO: LEGISLATURA 2015-2019. Brasília (DF): DIAP, 2014. (Estudos Políticos do DIAP). Disponível em: http://www.diap.org.br/index.php/publicacoes/finish/41radiografia-do-novo-congresso/2883-radiografia-do-novo-congresso-legislatura-2015-2019-dezembrode-2014. Acesso em: 16 jun. 2015.

: Legislatura 2019-2023. Departamento Intersindical de Assessoria Parlamentar. - Brasília, DF : DIAP, 2018. 164 p. : il. ; color. (Estudos Políticos do DIAP).

RIBEIRO, L. S. A palavra casamento em disputa no Brasil. 2012. Dissertação (Mestrado em Letras)Pontifícia Universidade Católica do Rio de Janeiro, Rio de Janeiro, 2012.

ROUDINESCO, E. 1944- A família em desordem. Tradução André Telles. Rio de Janeiro: Jorge Zahar, 2003. 
SALDANHA, N. O que é o Poder Legislativo. 5. ed. São Paulo: Editora Brasiliense. 1992. (Coleção Primeiros Passos)

SANTOS, S. M. M. 0 pensamento da esquerda e a política de identidade: as particularidades da luta pela liberdade de orientação sexual. Tese (Doutorado em Serviço Social) - Universidade Federal de Pernambuco, Recife, 2005.

Revista Ética. 2002.

O pensamento de esquerda e os limites da luta pela liberdade de orientação sexual.

SIMIONATTO, I. O social e o político no pensamento de Gramsci. Acessa.com, Juiz de Fora, 1997. Seção Gramsci no Brasil. Disponível em: http://www.acessa.com/gramsci/?page=visualizar\&id=294. Acesso em: 18. nov. 2015.

SOUZA, J. M. A. O conservadorismo moderno: esboço para uma aproximação. Revista Serviço Social e Sociedade, São Paulo, ano 35, n. 122, jun. 2015.

ZAMBRANO, E. et al. 0 direito a Homoparentalidade. Cartilha sobre as famílias constituídas por pais homossexuais. Porto Alegre. Instituto de Acesso a Justiça. 2006.

\section{Notas}

1 Optamos neste trabalho pelo uso do termo homoparental/família homoparental como posicionamento ético-político visto que, historicamente, o foco dado na orientação sexual dos pais/mães tem como objetivo demonstrar que indivíduos que fugiam a orientação heterossexual não são capazes de cuidar, criar filhos, exercer a maternidade/paternidade.

2 "Frentes Parlamentares são associações de membros do Legislativo Federal de vários partidos que decidem se juntar para promover o debate e a legislação sobre determinado tema de interesse da sociedade (http://www2.camara.leg.br/).

${ }^{3}$ Cenário que somente se agravou na nova legislatura. Conforme aponta a radiografia do novo congresso legislativo (20192023): "[...] o novo Congresso é o mais conservador dos últimos 30 anos. Pode ser classificado como: Liberal, do ponto de vista econômico; Fiscalista, do ponto de vista da gestão; Conservador, do ponto de vista dos valores; Mais à direita, do ponto de vista ideológico; e Atrasado em relação ao meio ambiente e aos direitos humanos" (RADIOGRAFIA, 2018, 29).

4 Logo, o discurso em voga sobre o fim da família, da destruição das famílias, cai por terra. Torna-se necessário compreender as mudanças pelas quais as famílias passaram e vêm passando para que se possa ter claro, que o potencial questionador da ordem posta deve integrar reflexões e estratégias que visam à elaboração de uma nova hegemonia (SANTOS, 2002).

5 Elisabeth Roudinesco é historiadora e psicanalista, e tem seus estudos voltados para o debate sobre famílias, parentalidade e união homoafetiva, com base na perspectiva da psicanálise. Cabe destacar que dialogamos com a autora no sentido de recuperar elementos históricos, mas não concordamos com as elaborações teóricas da autora em sua totalidade.

${ }^{6}$ Não podemos nos referir a esse segmento de forma totalizante, escapando de suas particularidades e disputas internas. Nesse sentido, é importante não generalizarmos a relação, por exemplo, entre religiões e sexualidades, pois, além da existência de Igrejas inclusivas que consideram a orientação sexual como uma criação de Deus, há divergências entre os membros de uma mesma instituição.

${ }^{7}$ Costa e Nardi (2015, p. 138) questionam essa escolha do afeto como justificativa para o reconhecimento dos casamentos de pessoas do mesmo sexo, devido às implicações políticas dessa justificativa. Os autores criticam que o reconhecimento dessa relação exigiu uma justificativa adicional, visto que somente a legitimidade social não foi evidente. 0 que implica em duas questões, a nosso ver, assim como para os autores. Os discursos passam a defender a junção do direito de amar com 0 direito de se casar em oposição à desconstrução do amor romântico, realizado historicamente pelo movimento LGBT+. Além disso, o risco de se pautar o debate sobre a opressão - o não reconhecimento - a partir de um ponto pessoal, 0 afeto. 
FAMÍLIA, HOMOSSEXUALIDADE E CONSERVADORISMO: discursos no Congresso Nacional brasileiro

${ }^{8} \mathrm{~A}$ regulamentação da relação homo na visão de alguns militantes e pesquisadores "centra-se na tendência para encaixar gays e lésbicas num suposto logos heterossexual do contrato de casamento, da coabitação obrigatória, da fidelidade e dos deveres econômicos" (ALMEIDA, 2006, p. 5).

${ }^{9}$ Realizamos uma análise sobre a temática de forma mais aprofundada. Ver: HORST, 2017.

10 Conforme demonstra Corrêa $(2008$, p.3) "embora a religião tenha sempre reivindicado um conhecimento e jurisdição especiais no que diz respeito à moralidade sexual, o Estado moderno não é neutro em relação a temas sexuais". Portanto, é preciso ter claro os fundamentos da sociabilidade burguesa desde a sua concepção como uma doutrina moral, pois mesmo com um Estado secularizado e laico, pode ser reproduzida uma política conservadora, quando se mistura moralidade com normas sexuais, baseados, por exemplo, no saber médico, biológico ou jurídico. Dito de outra forma, "embora o apelo à laicidade como contenção do extremismo religioso seja urgente e necessário, ele não é suficiente (CORRÊA, 2008, p. 5). 